\title{
Control of the repeatability of high frequency multibeam echosounder backscatter by using natural reference areas
}

\author{
Marc Roche $^{1}$ (1) Koen Degrendele ${ }^{1} \cdot$ Christophe Vrignaud $^{2} \cdot$ Sophie Loyer $^{2} \cdot$ Tim Le Bas $^{3} \cdot$ Jean-Marie Augustin ${ }^{4}$. \\ Xavier Lurton ${ }^{4}$
}

Received: 30 June 2017 / Accepted: 13 January 2018 / Published online: 23 January 2018

(c) The Author(s) 2018. This article is an open access publication

\begin{abstract}
The increased use of backscatter measurements in time series for environmental monitoring necessitates the comparability of individual results. With the current lack of pre-calibrated multibeam echosounder systems for absolute backscatter measurement, a pragmatic solution is the use of natural reference areas for ensuring regular assessment of the backscatter measurement repeatability. This method mainly relies on the assumption of a sufficiently stable reference area regarding its backscatter signature. The aptitude of a natural area to provide a stable and uniform backscatter response must be carefully considered and demonstrated by a sufficiently long time-series of measurements. Furthermore, this approach requires a strict control of the acquisition and processing parameters. If all these conditions are met, stability check and relative calibration of a system are possible by comparison with the averaged backscatter values for the area. Based on a common multibeam echosounder and sampling campaign completed by available bathymetric and backscatter time series, the suitability as a backscatter reference area of three different candidates was evaluated. Two among them, Carré Renard and Kwinte, prove to be excellent choices, while the third one, Western Solent, lacks sufficient data over time, but remains a valuable candidate. The case studies and the available backscatter data on these areas prove the applicability of this method. The expansion of the number of commonly used reference areas and the growth of the number of multibeam echosounder controlled thereon could greatly contribute to the further development of quantitative applications based on multibeam echosounder backscatter measurements.
\end{abstract}

Keywords Multibeam echosounder $\cdot$ Seafloor backscatter $\cdot$ Repeatability $\cdot$ Calibration $\cdot$ Reference area $\cdot$ Monitoring

\section{Introduction}

In Northwestern Europe, coastal marine areas have been under increasing pressure from industrial activities for more than three decades. Cumulative impact on marine habitats from activities such as trawl fisheries, dredging of aggregates and the development of wind farms has become

Marc Roche

Marc.Roche@economie.fgov.be

1 FPS Economy, Continental Shelf Service, 1000 Brussels, Belgium

2 Service Hydrographique \& Océanographique de la Marine (SHOM), Brest, France

3 National Oceanography Centre (NOC), Southampton, UK

4 Institut Français de Recherche pour 1'Exploitation de la Mer (Ifremer), Brest, France a serious concern for decision makers and environmental organizations alike, although these activities are usually subject to stringent regulations. At an international level, the European Union (EU) Marine Strategy Framework Directive (MSFD 2008), requires member states to monitor and assess the Good Environmental Status of the EU's marine waters in order to protect the marine environment more effectively. "Coastal waters, including their seabed and subsoil, are an integral part of the marine environment, and as such should also be covered by this Directive" (MSFD 2008 , page $164 / 20$, article 12 ).

Due to its ability to provide simultaneously bathymetry and seafloor backscatter data, multibeam echosounder (MBES) technology is an efficient tool to carry out such monitoring obligation. Pragmatically, the Good Environmental Status monitoring of the seabed can be organized by conducting successive MBES surveys on established reference areas and along reference tracks over medium-to-long-term time scales 
(months to years). The resulting bathymetry and backscatter time series should then be used to detect significant changes of the seabed over time and space. Obviously, such a "bathymetry and backscatter time series" approach implies at least the guarantee of a stable measurement system for the duration of the monitoring program.

While International Hydrographic Organization standards (IHO 2008) provide a framework for assessing the accuracy and the repeatability of bathymetric measurements, too little attention has been given to assess the quality level of MBES backscatter data. Although mentioned in the dedicated literature, the need for echo intensity calibration procedures has been the topic of a structured collaborative effort by the community only for a few years (Lurton and Lamarche 2015). Only recently, backscatter data became the subject of specific recommendations in the context of a reference document defining contract specifications for hydrographic surveys (Land Information New Zealand 2016). The delivery of factorycalibrated MBES by manufacturers would certainly constitute a solid foundation and impulse to help users to record and control absolute backscatter at a sufficient quality level (Lamarche and Lurton 2017): in this respect the offer of a user's service to establish a posteriori a relative backscatter calibration specific for individual MBES (Kongsberg 2017a) is a significant advance toward a better control of the backscatter data. However, a quality standard for MBES backscatter is not available at present. Consequently, no level of reliability can be connected to the final time series of seafloor reflectivity values, used by geoscientists as a proxy to highlight significant changes of the seabed. Defining quality standards for MBES backscatter measurements, estimating accuracy level and evaluating quantitative capabilities to monitor the seabed integrity remain critical challenges (Lurton and Lamarche 2015; Lamarche and Lurton 2017; Lucieer et al. 2017).

In the absence of an absolute calibration guaranteed by the manufacturer, the use of a natural reference area with stable and known backscatter can be considered as a pragmatic solution for users who need to evaluate the backscatter stability (Lurton and Lamarche 2015; Lurton et al. 2015). This paper focuses specifically on the MBES backscatter repeatability control. It evaluates through case studies, the advantages and the limitations of the use of natural reference areas for controlling the repeatability of MBES backscatter measurements.

\section{Problem definition}

\section{Repeatability control versus absolute calibration}

A distinction has to be made between repeated backscatter surveys undertaken with a single MBES and surveys made with several MBES. Each approach addresses different issues associated with the sensors: a regular check of the stability of the operated system for the former, and an absolute calibration that makes the datasets from different MBES comparable and consistent for joint processing for the latter (Fig. 1).

If repeated backscatter measurements undertaken using a single MBES are incorporated in a seafloor-monitoring program, the resulting backscatter data time-series are intrinsically relative: the backscatter data from a single MBES must be comparable between successive measurements. In this case, an absolute reference of the measured backscatter level is not mandatory, but a regular assessment of the backscatter measurement repeatability is required to detect possible drifts of the measuring system sensitivity. Such a relative assessment involves either metrological checking operations (ideally implying in-tank measurements of transmit and receive sensitivities), or more simply the recording of echoes from a stable reference target. For the latter, performing regular surveys on a natural reference area with a stable backscatter is a pragmatic solution to evaluate the repeatability of the backscatter measurements. The absence of any significant trend in the time series recorded on the reference area demonstrates the sensor stability. Based on this stability demonstration on a reference area, a significant trend of the backscatter level measured with the same MBES on other surveyed areas will be considered as reliable and reflecting a real change of the seabed.

The use of several MBES systems in a monitoring program implies to compare and merge backscatter data issued from the different MBES. In this case, in addition to the repeatability controls, an absolute calibration using a reference system is required for each MBES. Following this, the resulting measurements from each separately calibrated system can be fully compared and collectively used in the monitoring program.

Figure 1 summarizes the principle of the repeatability control (presented in this paper) with regard to the method used for the absolute calibration (see e.g. Eleftherakis et al. 2018). Obviously, the absolute calibration procedure involves much more technical means and constraints than the repeatability control. Moreover, taking into account this absolute calibration still requires further repeatability controls.

\section{Natural reference area requirements for backscatter repeatability control}

Several requirements are needed for a natural area to be used as a reference for absolute calibration of MBES backscatter (Lurton et al. 2015; Eleftherakis et al. 2018, Table 1). If predictability requirements are essential to establish an absolute calibration (Eleftherakis et al. 2018), stability of the area over time is paramount to ensure consistency with the repeatability control. 


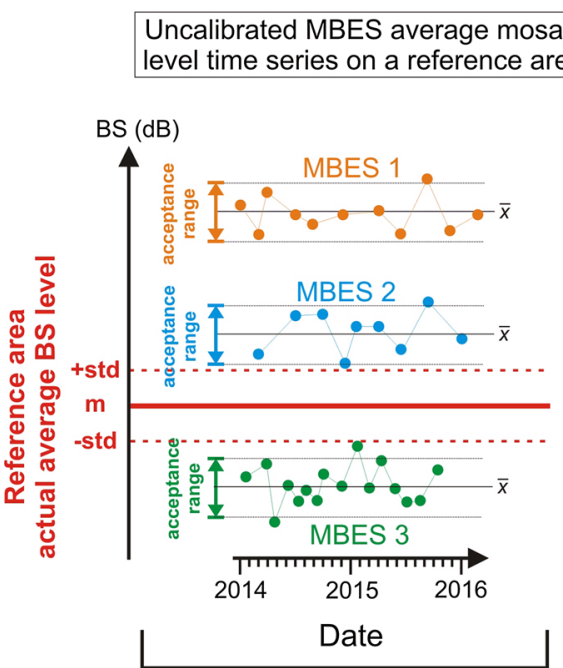

(a) Repeatability control

Fig. 1 MBES backscatter repeatability control (this paper) versus absolute calibration (Eleftherakis et al. 2018) on reference area a Repeatability control: for each MBES, successive measurements made on a reference area where mean backscatter level is presumed stable are used to evaluate the repeatability level of each system. A common acceptance range must be defined to exclude outlier surveys

Indeed, the control of the MBES backscatter measurement repeatability mainly relies on the assumption of a sufficiently stable reference area (regarding its backscatter signature) at the time scale of the monitoring program. The variation of measured mean backscatter levels from successive surveys of the reference area must remain below a conventional tolerance threshold, low enough in relation to the accuracy required to detect a significant change of seabed characteristics.

To avoid circular reasoning, the stability of the reference area should be assessed using only bathymetry and geomorphology, i.e. independently of the backscatter. In dynamic
Uncalibrated MBES angular response on a reference area

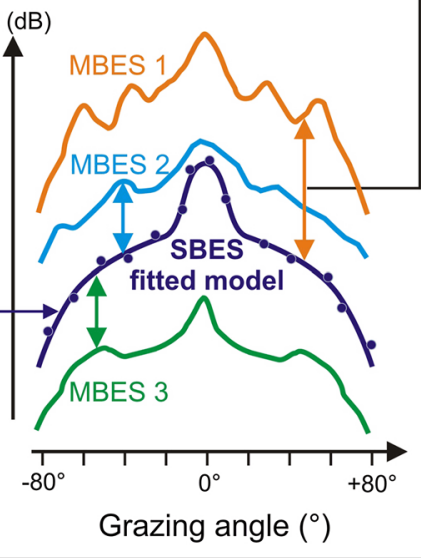

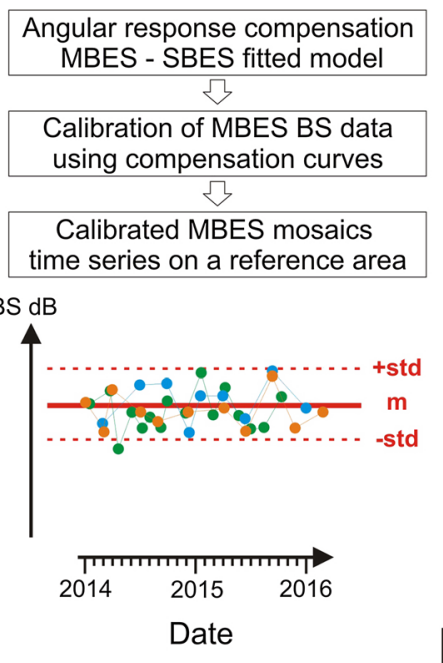

(b) Absolute calibration

from the time series, b Absolute calibration: the angular response model obtained from a fully calibrated single beam echosounder (SBES) on the reference area is used as an absolute reference to calibrate each MBES. At the end of this cross-calibration process, the calibrated MBES backscatter mosaics and time series from different MBES are all comparable

coastal environments, the absence of accretion or erosion and a stable morphology of a reference area guarantee a good level of stability of its sedimentary cover (Dronkers 2016) and consequently of its mean backscatter level.

Current hydrographic processing standards and criteria can be used to quantify the level of bathymetric stability of a reference coastal area at a typical decimeter scale. If the bathymetric average of individual surveys of the reference area remains confined within the IHO Special Order interval (IHO 2008) around the overall time series mean and no drift of the individual means is observed within a sufficient time

Table 1 Backscatter reference area requirements
Main requirements

Mean backscatter level stability

Backscatter predictability

\begin{tabular}{ll}
\hline Morphology and sediment characteristics & Backscatter characteristics \\
\hline Flat and regular morphology & High backscatter strength \\
Simple unidirectional patterns acceptable & Spatial isotropy \\
Coarse (gravel, gravelly sand) sediment cover & Angular isotropy: \\
Homogenous sediment cover & O Slow variation with vertical angle \\
& O Minimum specular effects \\
& O No dependence in azimuth (stable depend- \\
& ence acceptable)
\end{tabular}

Scale requirements

Practical-legal requirements

Depth compatible with MBES far-field

Easily accessible, but little frequented

Dimension compatible with MBES coverage
Open-science compliant 
interval (several years), the bathymetric stability is reasonably demonstrated.

In terms of resolution, the level of assessment of the bathymetric and morphological stability of a reference zone depends on the spatial gridding applied to the MBES data, i.e. the sounding spacing (given across-track by the interbeam spacing and along-track by the ping rate and ship's speed), which limits the level of detail accessible to measurement. However, changes of the sedimentary interface at a spatial scale smaller than the MBES elementary measurement resolution (approximately and conveniently given by the extent of the beam footprint on the seafloor) may happen, induced by e.g., changes of benthic fauna and related bioturbation, benthic flora, oscillations of sand ripples. Such small variations potentially cause fluctuations of the average backscatter (small causes can here have large effects) without being detectable in the bathymetric data; this illustrates the limitation of a stability assessment based only on the sounder-measured morphology. For this reason, regular in situ controls of the seabed interface including sediment sampling and video imaging, in addition to acoustic data, are highly recommended to confirm seabed stability.

\section{Materials and methods}

\section{Survey areas}

Three shallow water areas-Carré Renard, Kwinte and Western Solent-located in distinct geographical areas (Fig. 2) illustrate the feasibility and the issues of using natural areas for assessing the repeatability of backscatter measurements from MBES systems.

These reference areas are used by research teams working in various fields such as fundamental and applied research in oceanography and marine geology, hydrography, scientific equipment engineering on research vessels, control of the sand extraction impact on marine habitats and marine science education. The teams involved in this research converge on the need to monitor the stability of backscatter measurements from their own equipment; however, given their diversity of interests and obligations, the amount and type of scientific data dedicated to that objective greatly varies from one reference area to another. For instance, only the Carré Renard and Kwinte areas were subject to repeated backscatter measurements with a same MBES on a multi-year time period making possible a formal stability level assessment. The backscatter time series acquired on Carré Renard and Kwinte areas lead to the proposition of practical criteria for backscatter level stability and the evaluation of their relevance as a reference area for backscatter measurements.
A joint survey was conducted in June 2015 aboard RV Belgica (RV Belgica cruise \#16 report 2015) over the three areas. Complementary to MBES measurement, groundtruthing operations were undertaken, including video footage of the sedimentary interface at selected locations and sediment sampling using a Reineck box-corer. The objective was multi-fold: evaluation of the bathymetric quality level (according to IHO S44) and backscatter calibration of the MBES aboard Belgica on Carré Renard reference area; comparison of the backscatter characteristics measured on the three areas; and evaluation of the impact of acquisition parameters and the navigation azimuth on the mean backscatter level. The data collected during this survey on Carré Renard, Kwinte and Western Solent areas provide a solid base to compare and discuss the prevailing conditions for the validation of these areas as benchmarks for stability assessment of the MBES backscatter level. The same dataset is used to gauge the critical acquisition parameter settings ensuring data comparability within a backscatter time series.

\section{MBES backscatter acquisition and processing}

The bathymetric and backscatter data presented in this work were all acquired at a frequency of $300 \mathrm{kHz}$ with various models of Kongsberg shallow-water MBES installed on different hydrographic and research vessels. Table 2 provides the MBES models used against the data types presented in the three case studies. The technical specifications of these MBES systems are available on the Kongsberg website (Kongsberg 2017b).

The comparability of distinct backscatter measurements from the same MBES implies that the combined emission level and reception sensitivity are calibrated and stable from one survey to another. Similar acquisition settings (runtime parameters/filter and gain values) were applied from one survey to another as recommended by Rice et al. (2015). In particular, the pulse duration which determines the instantaneous insonified area that is critical for the backscatter level determination (Hughes Clarke 2012) was kept around a same value in order to ensure the comparability between the individual measurements of the backscatter time series. Considering the wealth of settings and options available in today's MBES, it is not straightforward to ensure stable acquisition settings during an entire cruise when a system is operated by several operators, during different shifts and on various areas. A series of lines per setting were performed following the same positions to empirically evaluate the impact of each change of setting on the average backscatter level, all other conditions being equal. The level of comparability of the backscatter data has been thus evaluated for each setting.

Backscatter post-processing was considered with great care, due to its impact on the final reflectivity levels. In the 

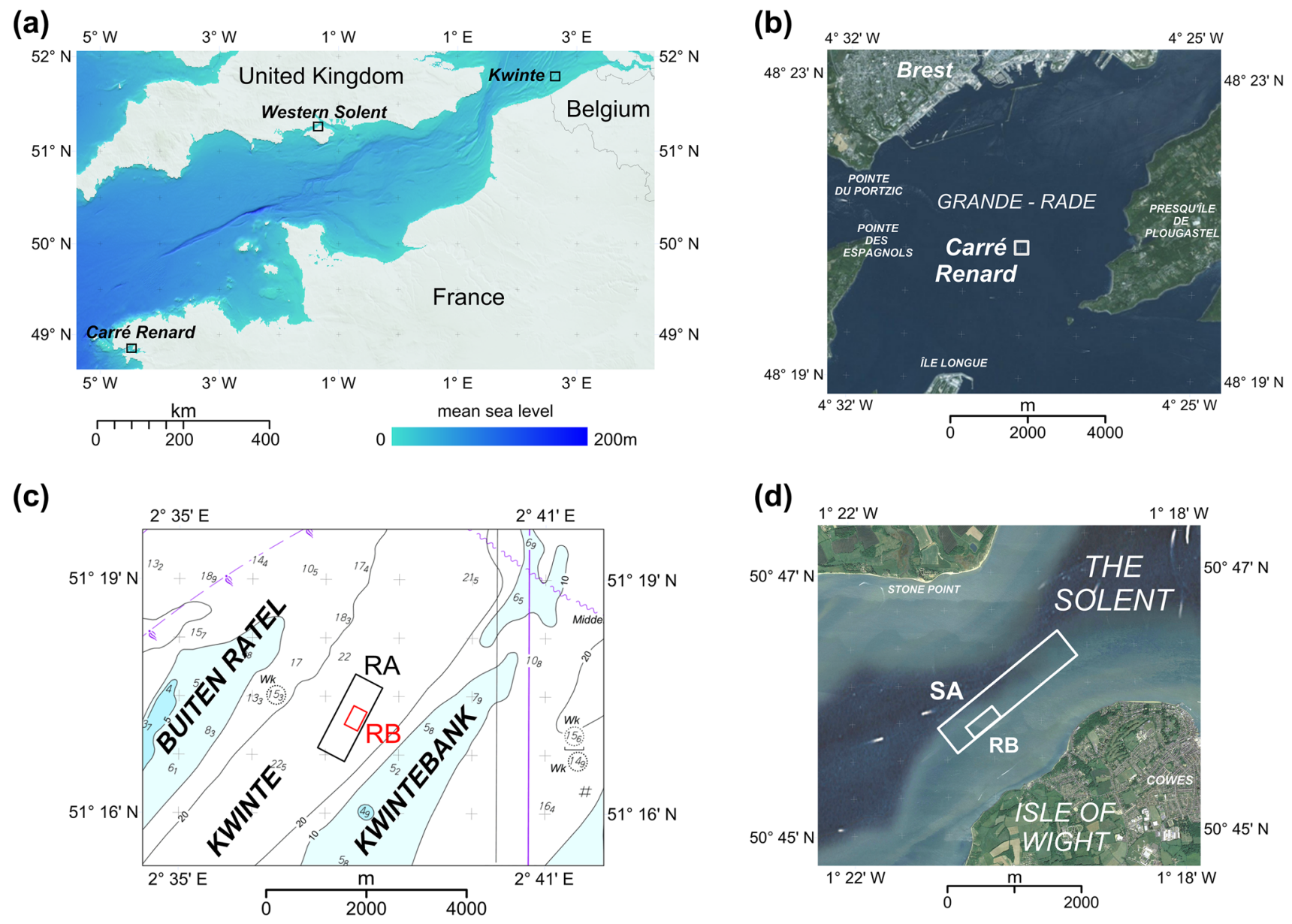

Fig. 2 Locations of the three survey areas. a Overview: General Bathymetric Chart of the Ocean 30 arc-second GEBCO_2014 grid (GEBCO 2014). b Carré Renard reference area location in the Grande Rade de Brest (France), central coordinates of the area $48^{\circ} 20.419^{\prime} \mathrm{N}-4^{\circ} 28.770^{\prime} \mathrm{W}$, background: World Imagery (2017). c Kwinte reference area location in the Flemish bank area (Belgium), $R A$ reference area for the bathymetry, $R B$ reference sub area for the backscatter, central coordinates of RA area $51^{\circ} 17.184^{\prime} \mathrm{N}-2^{\circ} 37.73^{\prime} \mathrm{E}$, background: Vlaamse Hydrografie (2014). d Western Solent reference area location in the Western Solent (United Kingdom), $S A$ survey area, $R B$ reference sub area for the backscatter central coordinates of the SA area $50^{\circ} 45.895^{\prime} \mathrm{N}-1^{\circ} 20.545^{\prime} \mathrm{W}$, background: Google Earth (2017)

Table 2 MBES models used for each case study and data type

\begin{tabular}{lll}
\hline Case study & Data type & MBES \\
\hline Carré Renard & Bathymetric and backscatter model & Research Vessel Belgica EM 3002-D \\
& Bathymetric time series & SHOM Hydrographic Vessels EM 3002 and EM 2040 \\
Kwinte & Backscatter time series & Ifremer Research Vessel Thalia EM 2040-D \\
& Bathymetric and backscatter model & Research Vessel Belgica EM 3002-D \\
& Bathymetric time series & \\
Western Solent & Backscatter time series & Research Vessel Belgica EM 3002-D \\
\hline
\end{tabular}

context of a seabed monitoring program, backscatter time series are used as a proxy to detect changes in the nature of the seabed or to assess the stability of a measurement system. Here, processing tools and procedures were kept stable from one survey to the other in order to guarantee the comparability of the results. For the Carré Renard and Kwinte areas, the backscatter data have been thoroughly processed using the procedure described in Table 2, using 
Ifremer's SonarScope ${ }^{\circledR}$ software (Augustin 2016). The Western Solent backscatter data have been processed with QPS FMGT® using the default settings (QPS FMGT 2017).

The backscatter time-series approach is quite different from backscatter mapping and seabed classification which require radiometric and geometric corrections. Indeed, beam-pattern correction and compensation of the backscatter angular dependency are necessary to provide an artefactfree final mosaic, allowing a classification of the acoustic information that can be correlated with the seabed geology and habitat types (see Lucieer et al. 2017 for examples). In this study, i.e. a seafloor-monitoring context, the corrections for level attenuation and instantaneous insonified area are sufficient for a robust comparison of the backscatter levels acquired with a same MBES on a same seabed area at different times; beam-pattern corrections and angular compensations are not necessary in this context. In order to detect a possible drift of backscatter without an absolute calibration curve, the backscatter data is used without any prior angular compensation. The angular sector that best discriminates the different types of sediment is the oblique-incidence sector often forming a plateau within approximately $\pm\left[30^{\circ}, 50^{\circ}\right]$ (APL 1994; Lamarche et al. 2011). Here, we consider that variations in the nature of the seabed will be reflected by a significant variation in the average level of backscatter measured in this particular angular sector. Hence, a standard backscatter processing can be proposed that provides an average backscatter level for each survey in the time series (Tables 2, 3).

Significant differences (up to $5 \mathrm{~dB}$ ) have been observed between mean backscatter levels measured from a common dataset processed by different backscatter processing software (Lucieer et al. 2017). This inconsistency seriously hinders the integration within a same time series of backscatter mean levels and standard deviations calculated with different software. In a monitoring framework, it is recommended to process the backscatter data with the same software following a stable procedure keeping the same settings. More generally, the need for comparative studies (e.g. in the context of the Backscatter Working Group work program, Lurton and Lamarche 2015) to identify and document the discrepancies introduced by different software suites over a same dataset and regarding basic processing operations, can be argued.

Finally, series of individual survey values - mean backscatter level and standard deviation-as a function of time (e.g. as graphical representations) make it possible to evaluate whether the backscatter measurements are stable (Fig. 1a). Two elements must be considered to assess this stability: the magnitude of the difference between the individual values and the overall average and the presence (or the absence) of a significant trend. The detection of mean backscatter levels deviating too much from the overall average value implies the definition of an acceptance range beyond which individual mean values are considered as outliers reflecting sudden changes in the backscatter level. Such sudden changes can have various causes other than a significant variation in the seabed properties: changes in acquisition parameters such as pulse length, antenna failure, bad sea conditions during the recording, deteriorations of the signal-to-noise ratio, etc. These atypical values require thorough investigation before deciding on their exclusion from the time series. From a statistical point of view, the range acceptance can be based on the confidence interval associated with the overall average value; the width of this interval varies from one monitoring area to another and relates inversely to the data density over time. Within the same area, this confidence interval changes with each addition of a new individual mean value to the time series.

A more pragmatic approach is to consider a fixed tolerance threshold based on the level of inherent uncertainty of the backscatter measurement due to echosounder sensitivity. For current MBES, this level of uncertainty is typically around $1 \mathrm{~dB}$ (Hammerstad 2000). On the other hand, in the $\pm\left[30^{\circ}, 50^{\circ}\right]$ angular range, the mean difference between average backscatter levels of different typical sediments is 2-3 dB (APL 1994), meaning that a $1 \mathrm{~dB}$ difference is halfthe-way between two neighboring granulometric classes of sediment (e.g. fine sand and medium sand). Hence, in a time series, the backscatter stability domain can be defined using a threshold of $1 \mathrm{~dB}$ on either sides of the overall mean. Temporal variations remaining below this $\pm 1 \mathrm{~dB}$ limit are considered as insignificant trends at the scale of the time series.
Table 3 Backscatter processing steps for time-series analysis in a monitoring context. Processing code A4 B0 C0 D0 E5 F0 according to the nomenclature of processing levels proposed by Lamarche and Lurton (2017)

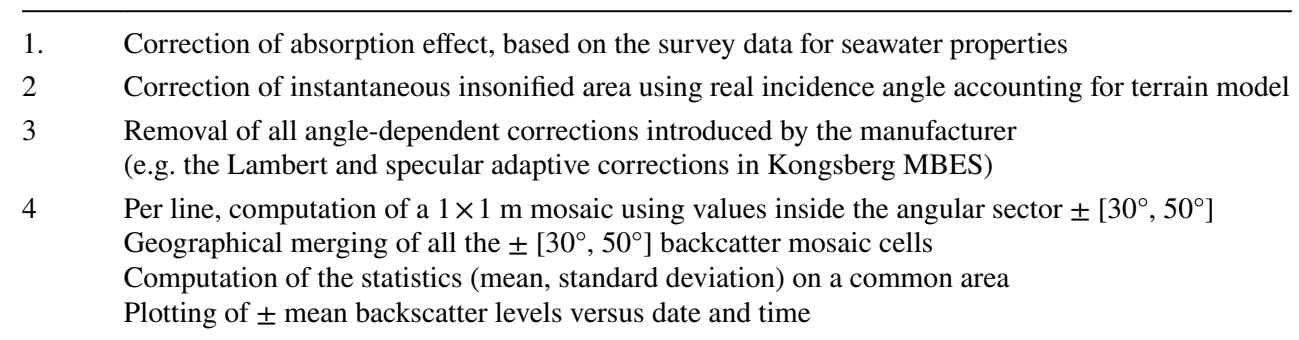




\section{Case studies}

\section{Carré Renard reference area}

Carré Renard reference area is located in the sheltered central part of the Bay of Brest, France (Fig. 2a, b). This survey site of $0.16 \mathrm{~km}^{2}(0.4 \times 0.4 \mathrm{~km})$ with an average depth of $19.4 \mathrm{~m}$, was selected for its flat and homogeneous seafloor (Fig. 3a, b; see also Lurton et al. 2017) and has been used by the French Service Hydrographique et Océanographique de la Marine (SHOM) as a bathymetric reference area to assess the hydrographic quality of its shallow-water sonar systems.

The Bay of Brest is a macrotidal area characterized by a semi-diurnal tide; the tidal currents may reach $2.5 \mathrm{~m} / \mathrm{s}$. Carré Renard is off-centered with respect to the channel entrance with consequently a lower maximum tidal current around $1.5 \mathrm{~m} / \mathrm{s}$.

Carré Renard hosts a population of a small echinoderm (Ophiocomina nigra) structuring the benthic habitat (Blanchet-Aurigny et al. 2012). This population has been monitored many times since the 1990s, with the conclusion that after an increase of the population between early 1990s and 2011, the density and structure of the seabed are now stable and do not show significant seasonal fluctuations (BlanchetAurigny, pers. comm.). Some ground-truth observations (samples and videos) from the RV Belgica cruise \#2015/16 are presented in Fig. 4a, b.

Video images suggest a sandy gravelly seabed with abundance of pebbles. Ophiocomina nigra is omnipresent and profuse throughout the area. Locally, the seabed is also lined with Crepidula fornicata shells (Fig. 4a top of images V4 and V5 and Fig. 4b CR_S4_1_2_mG). The grain-size analysis of box-cores classifies the samples into the muddy Gravel and muddy sandy Gravel areas of the
Gravel-Mud-Sand triangle (Folk 1954) or more globally in the mixed sediments area sensu Long (2006). From an acoustic point of view, despite a mud matrix, the absence of bedforms and the mixed nature of the sediment marked by the abundance of echinoderms, shells, gravel and pebbles demonstrate a high roughness and isotropic interface. Carré Renard isotropy is confirmed by the stability of the MBES backscatter levels measured in different directions of navigation (Lurton et al. 2017).

Since 2005, numerous surveys have been conducted by SHOM with several Kongsberg MBES (EM 3002 and EM 2040) installed on different vessels. Figure 5 presents the bathymetric time series of the Carré Renard area obtained from these surveys. Individually, all these surveys are IHO-S44 Special Order compliant.

The overall bathymetric time series reveals a slight (but significant) positive trend of $20 \mathrm{~cm}$ over a period of 11 years and 8 months. The variations of the mean depths between the different surveys remain within the IHO Special Order limits (IHO 2008) around the overall mean. The standard deviations remain stable, around $0.3 \mathrm{~m}$. One cannot exclude a link between this slight trend and the upgrade of SHOM's MBES (between 2012 and 2014) from Kongsberg EM 3002 to more accurate EM 2040 systems. However, a slight accretion cannot be excluded as this trend extends beyond this equipment change until the latest measurements. Although still included in the IHO S44 Special Order limits boarding the overall mean, two surveys (27/01/2010 and 24/03/2010) provide abnormally low mean depths beyond twice the standard deviation below the overall mean.

Only four surveys acquired over the 2014-2017 period with the same MBES and with the same settings are available to evaluate the backscatter stability of Carré Renard.
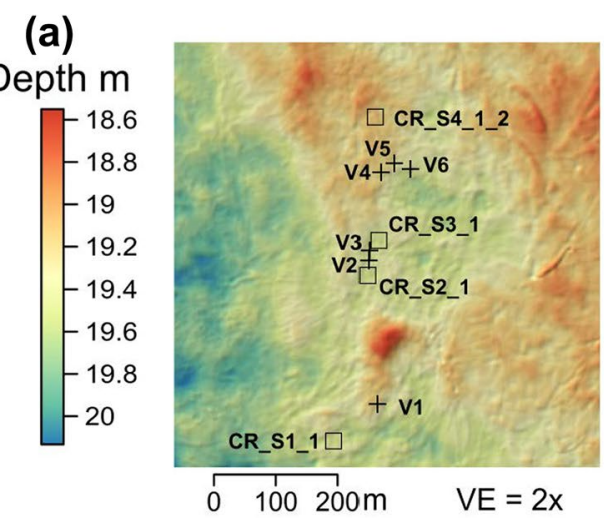

Fig. 3 Bathymetry and backscatter of Carré Renard reference area. a Bathymetric model (resolution $=1 \times 1 \mathrm{~m}$, vertical exaggeration $\mathrm{VE}=2 \mathrm{x}$ ) and location and labels of some of the ground-truth observations (samples $=$ square; video images $=$ cross; 11 June 2015). b (b)

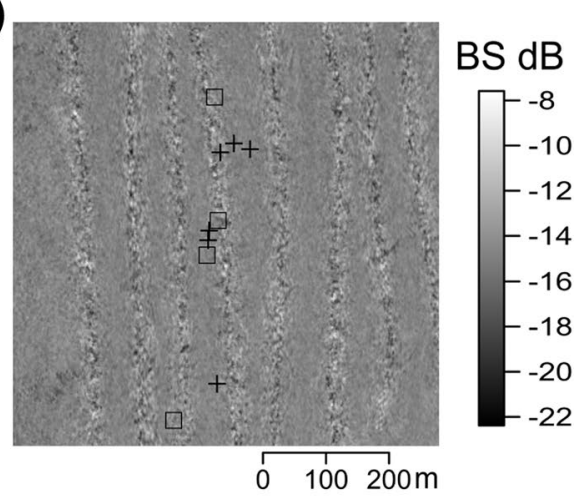

Backscatter mosaic with location of the ground-truth observations (resolution $=1 \times 1 \mathrm{~m}$ ). (Data from RV Belgica cruise \# C2015/16 EM 3002-D survey; 11 June 2015) 
(a)
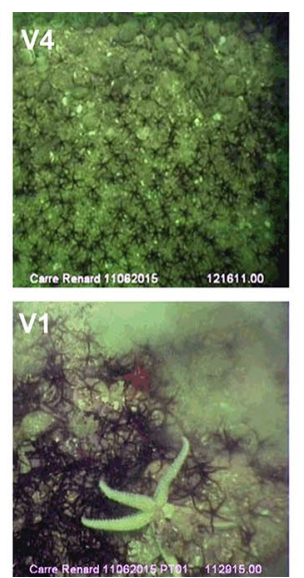
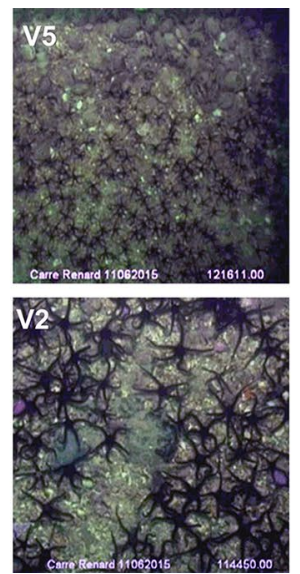
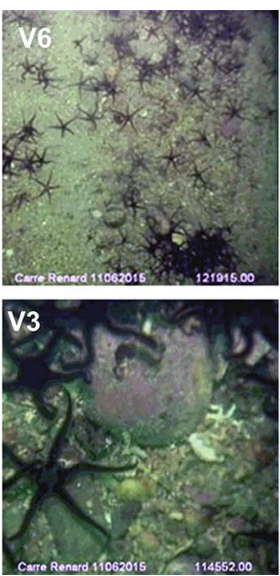

(b)

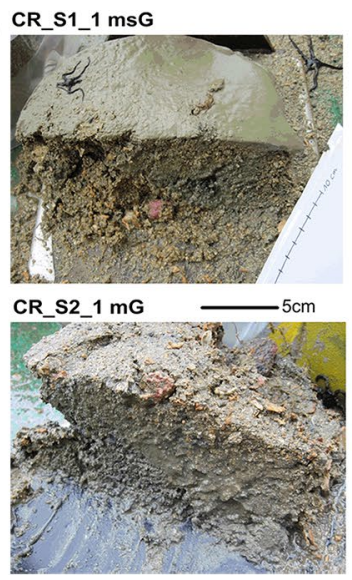

CR_S3_1 mG

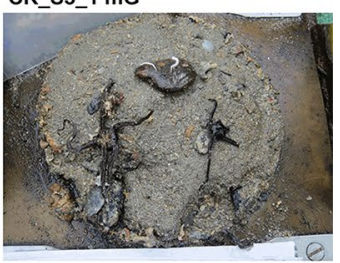

CR_S4_1_2 mG $5 \mathrm{~cm}$

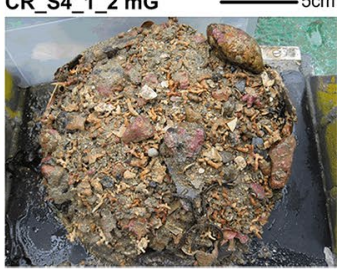

Fig. 4 Carré Renard ground truth information from 11 June 2015 (see Fig. 3a for location). a Video images (variable scale, Ophiocomina nigra rigid central disc diameter $=2-3 \mathrm{~cm}$ ). b Reineck box-corer samples

Fig. 5 Carré Renard reference area bathymetric time series from 2005 to 2017, compared to IHO Special Order (SO) recommendations. (Data from various SHOM hydrographic vessels operating Kongsberg EM 3002 and EM 2040)

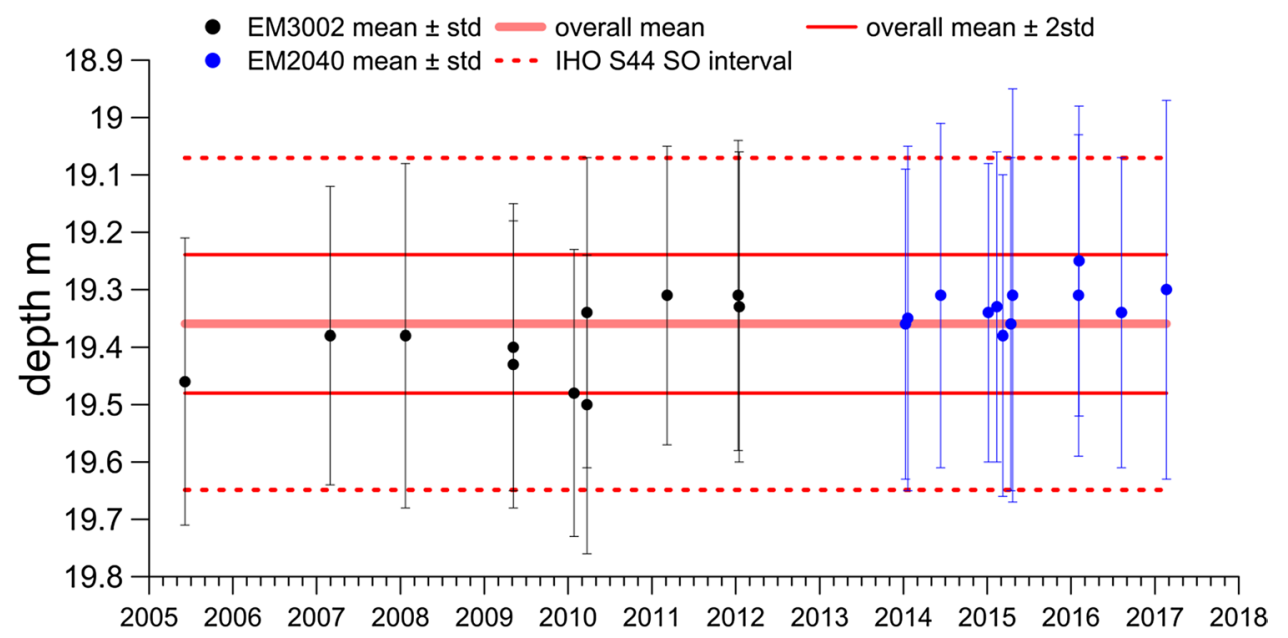

Average backscatter values in the $\pm\left[30^{\circ}, 50^{\circ}\right]$ sector are synthetized in Fig. 6.

The average backscatter levels recorded annually from 2014 to 2017 remain confined within $\pm 0.2 \mathrm{~dB}$ on each sides of the overall mean level $(-14.7 \mathrm{~dB})$; so no trend can be observed within this time interval. The spatial dispersion as measured by the standard deviation ranges between a minimum of $1.2 \mathrm{~dB}(2015)$ and a maximum of $1.9 \mathrm{~dB}$ (2017); yet it is difficult to interpret this modest variation as intrinsically linked to the seabed properties or to the unavoidable changes in the measurement configuration (available quantity of data used in the analysis). This average echo level stability combined with the bathymetric evolution confirms the quality of Carré Renard as a backscatter reference area. The assessment of this stability will continue in the upcoming years, along with the increasing use of this area as an active spot for shallow-water MBES calibration.

\section{Kwinte reference area}

The Kwinte reference area off the Oostende harbor in Belgium, is located in the Flemish sandbanks area of the Belgian part of the North Sea inside the Kwinte channel between the Kwintebank and the Buiten Ratel tidal sandbanks (Fig. 2a, c). The Kwinte area is oriented at $\mathrm{N} 60^{\circ}$ and covers $0.96 \mathrm{~km}^{2}(1.6 \times 0.6 \mathrm{~km})$. With water depths ranging from 23 to $26 \mathrm{~m}$, the Kwinte area is approximately flat (Fig. 7a). Slope breaks affect its southern part. They are related to a differential erosion of the tertiary Ypresian clay (Kortrijk Formation) directly underlying the gravel cover in this place (Liu et al. 1992). The NW part is shaped by a network of small to medium dunes (sensu Ashley 1990) of 10-30 m wave length and 0.2-0.3 m amplitude with crests oriented at $\mathrm{N} 320^{\circ}$ (Fig. 7). No dunes are observed using MBES in the SE part of the Kwinte area which is dominated by rounded and irregular hills and depressions of decimetric height forming a typical 
Fig. 6 Carré Renard reference area backscatter time series from 2014 to 2017. (Data from Ifremer RV Thalia Kongsberg EM 2040-D at $300 \mathrm{kHz}$ )

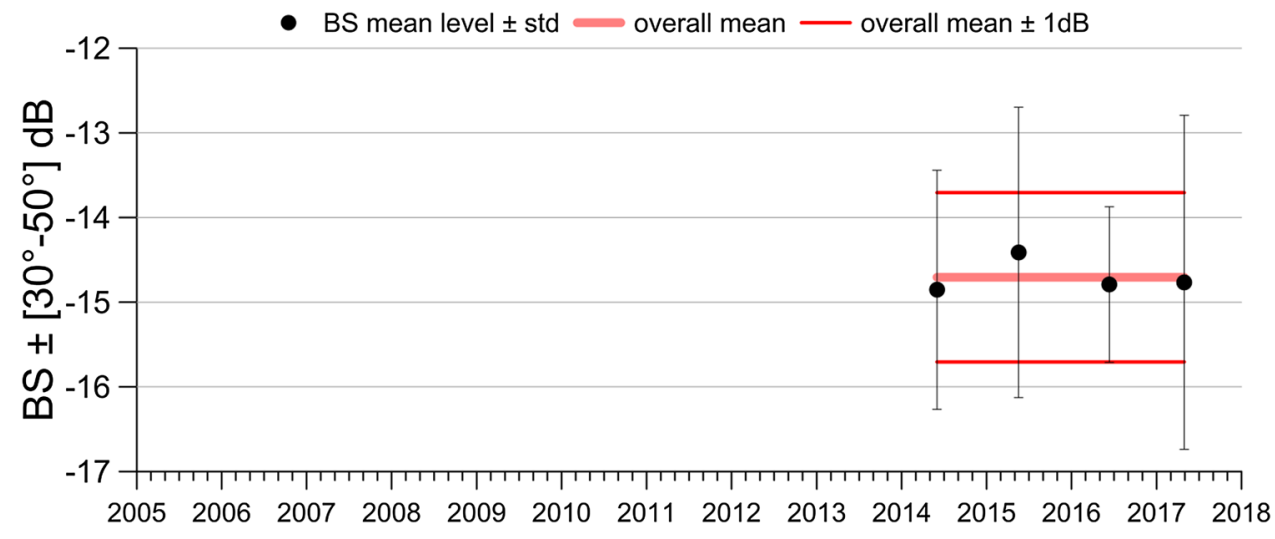

(a) scatter of the Kwinte reference area; RA: reference area for bathymetry; RB: reference sub area for backscatter. a Mean bathymetric model of RA (resolution $1 \times 1 \mathrm{~m}$, vertical exaggeration $\mathrm{VE}=5 \mathrm{x}$ ) with the location and label of the Sediment Profile Imager (SPI) stations (RV Simon Stevin Cruise 14-470, 14 July 2014). b Backscatter mosaic of RA (resolution $1 \times 1 \mathrm{~m}$ ). [MBES data from RV Belgica cruise \# C2012/14 EM 3002-D survey (18 September 2012) with the location of the Sediment Profile Imager (SPI) stations (RV Simon Stevin Cruise 14-470, 14 July 2014)]

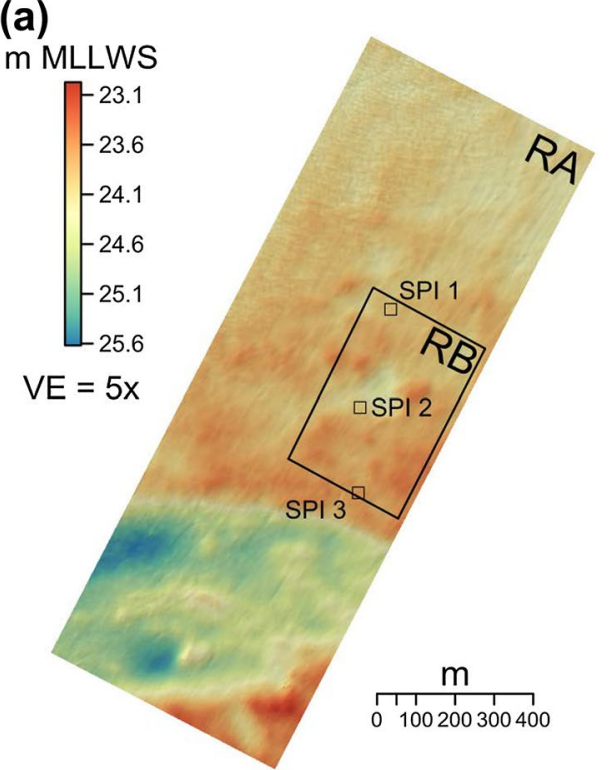

hillocky morphology characteristic of the flat gravel areas of the gullies in the Belgian part of the North Sea (Fig. 7). In the Kwinte channel, tidal currents can reach up to $1 \mathrm{~m} / \mathrm{s}$ during periods of spring tides and remain around $0.5 \mathrm{~m} / \mathrm{s}$ during neap tides. The current tidal ellipses are strongly elongated along the main axis of the channel (Van den Eynde et al. 2010).

The Kwinte area was initially selected in 2003 as a locus typicus gravel area to establish a classification system for backscatter data from a 100-kHz Kongsberg EM 1002 MBES, requiring the definition of acoustic classes on homogenous sediment areas (Roche 2002). Since 2009, regular surveys of this area have been carried out by the Continental Shelf Service of the FPS Economy of Belgium and by the Coastal Division-Flemish Hydrography of the Afdeling Kust. Inside the SE part of this area, a subarea of $0.12 \mathrm{~km}^{2}\left(0.4 \times 0.3 \mathrm{~km}^{2}\right)$ is proposed as a backscatter reference area (Fig. 7).
The multi-year bathymetric time series confirms the bathymetry stability of the area (Fig. 8). All bathymetric surveys since 2009 with RV Belgica EM 3002-D are compliant with IHO Special Order recommendations (IHO 2008): the survey averages are all included within both IHO and $\pm 2 \sigma$ limits ( $\sigma$ is here the standard deviation of the sounding values) around the overall mean and no significant trend is observed. The Kwinte reference area can be considered as stable regarding bathymetry, with neither significant accretion nor erosion. Moreover, the quasi-fixed location of the boundary between the NW dunes subarea and the SE hillocky subarea, confirms the excellent stability of the morphological structures on the Kwinte area.

The nature of the Kwinte area sedimentary cover (sandy gravel rich in shell fragments) is demonstrated by a series of grab samples collected in 2002 (Roche 2002) and by cross section images of the seabed taken in 2014 with a Sediment Profile Imaging system (SPI, Fig. 9). Overall, the sedimentary cover of the Kwinte backscatter reference area consists 
Fig. 8 Bathymetric time series of the Kwinte reference area. (Data surveyed by the FPS Economy-Continental Shelf service operating the Kongsberg EM 3002-D MBES on RV Belgica)

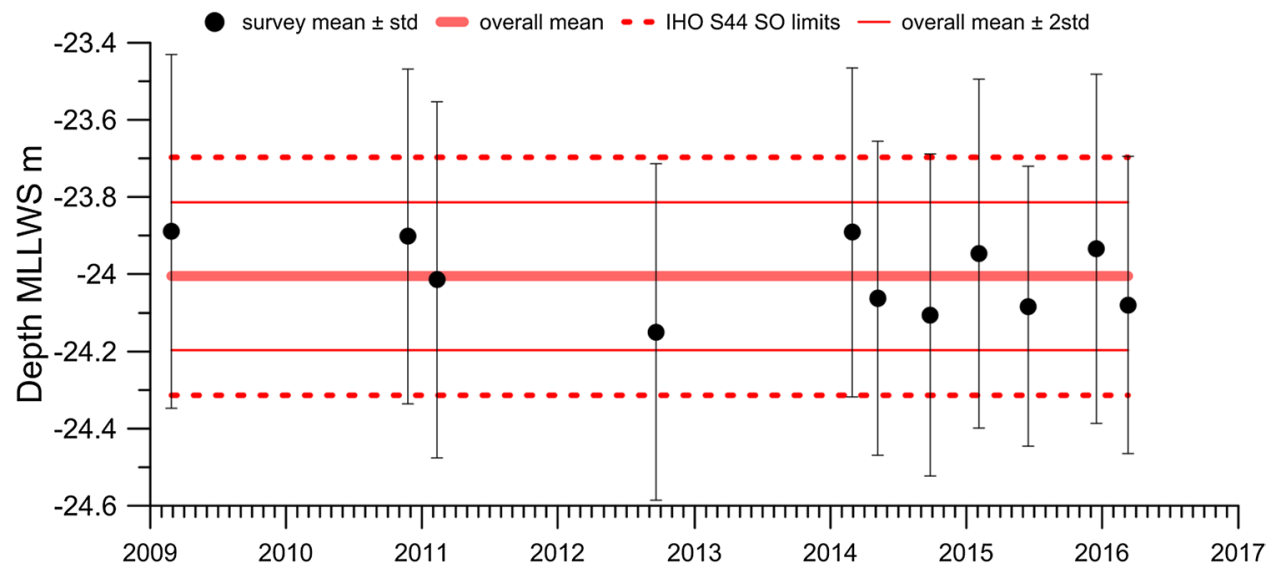

of gravelly Sand $(g S)$ and sandy Gravel $(s G)$ (Folk 1954) with a high carbonate content exceeding $15 \%$. These polygenic gravels that line the channels of the Flemish sandbanks correspond to lag deposits linked to a differential erosion by tidal currents of the holocene gravel deposits (Tytgat 1989). SPI images confirm the ubiquity and abundance of shell fragments on the surface of the sediment. Their influence on the backscatter level has been demonstrated as essential (Stanic et al. 1988).

Due to the uniform sandy gravelly cover, the area is acoustically isotropic. This is confirmed by backscatter measurements along varying directions done in June 2015 with the RV Belgica EM3002d (RV Belgica cruise \#16 report 2015), resulting in comparable mean values and standard deviations for the same angular interval in all directions.

The Kwinte backscatter time series is presented Fig. 10. No clear trend can be observed. The successive mean backscatter levels recorded with the RV Belgica EM 3002-D from 2009 to 2015 are confined within the $\pm 1 \mathrm{~dB}$ interval around the overall mean with the exception of the measurement carried out in November 2011 which is significantly lower. This discrepancy corresponds to a biofouling event: strong barnacle biofouling of the transducers was observed during the 2011-2012 winter dry-docking, requiring thorough cleaning and a new antifouling coating. A synchronous effect has been observed on other monitoring areas with distinct water depth, geomorphology and hydrodynamic conditions, demonstrating the correlation of this backscatter drift with the antennas biofouling (Rice et al. 2015). With clean antennas, the backscatter repeatability of the Belgica MBES on the Kwinte reference area is satisfactory as demonstrated by the measurements from 2014 to 2016.

Several backscatter time series acquired on different monitoring areas on sandbanks of the Belgian part of the North Sea with the RV Belgica EM 3002-D and processed in exactly the same way as the backscatter data from the Kwinte reference area, show significant variations and trends that go beyond the $\pm 1 \mathrm{~dB}$ interval around the overall mean. These backscatter variations are correlated with the intensity of the sand extraction which ostensibly modifies the sedimentary interface (Roche et al. 2017). As a counter-example, these time series showing significant variations of the mean backscatter level, validate the approach proposed in this paper.

On the Kwinte reference area, seabed anthropic alteration cannot be overlooked, as trawling marks are clearly visible on some backscatter mosaics (Fig. 11). By scraping and ploughing the sedimentary interface, trawling induces a direct physical impact on the seabed morphology and habitat (Palanques et al. 2014), depending on the sediment type and compaction (Rivera at al. 2017). On backscatter mosaics, the trawling marks of the Kwinte area are visible through pairs of lineaments (one per trawl) of noticeable high backscatter level that can be traced over long distances across
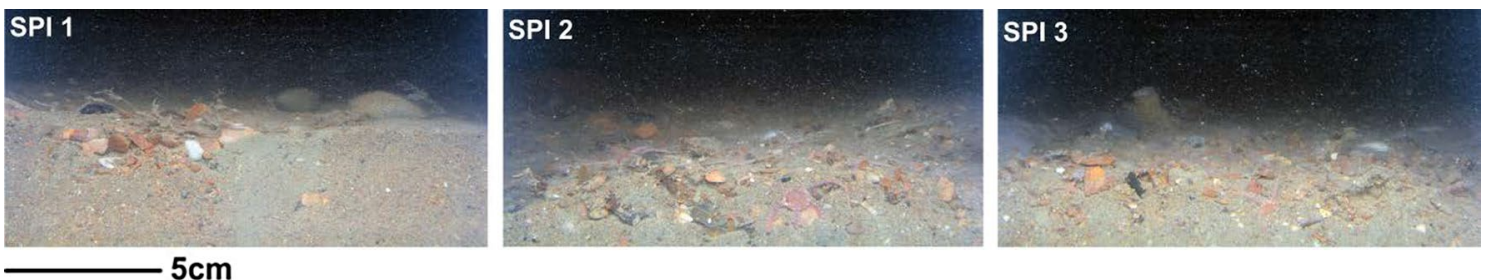

Fig. 9 Sediment Profile Imager (SPI) images of the seabed inside the Kwinte backscatter reference subarea. Location in Fig. 7b. RV Simon Stevin Cruise 14-470, 14 July 2014. Same scale for the 3 images 
Fig. 10 Backscatter time series of the Kwinte area. Backscatter mean level \pm standard deviation inside the angular sector $\pm\left[30^{\circ}, 50^{\circ}\right]$. Data surveyed by the FPS Economy-Continental Shelf service with the RV Belgica Kongsberg EM 3002-D. The vertical lines in 2001 and 2014 mark the RV Belgica dry-docking periods during which a significant biofouling of the MBES antennas has been observed and cleaned

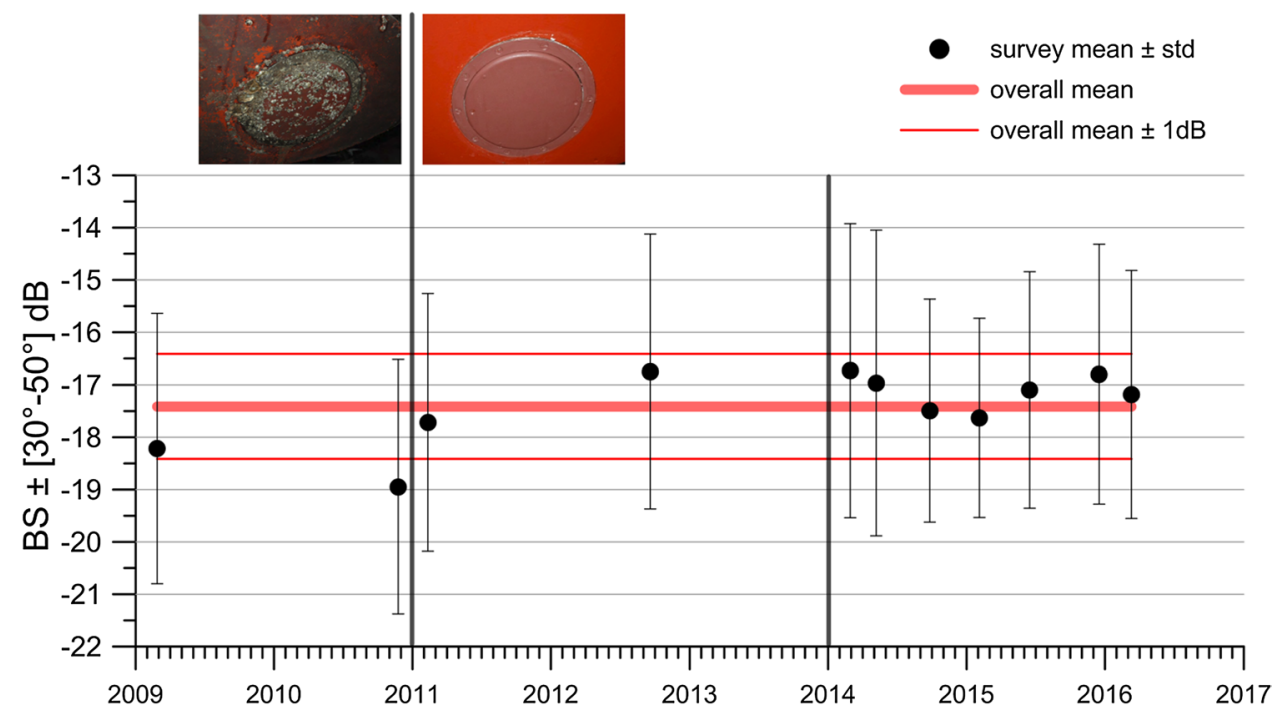

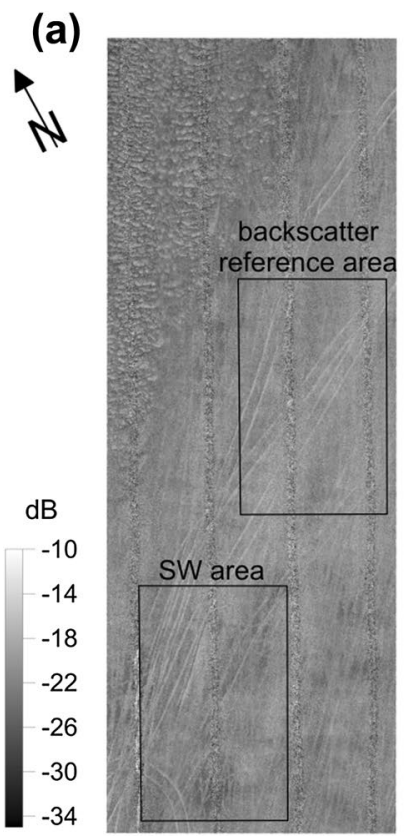

(b)

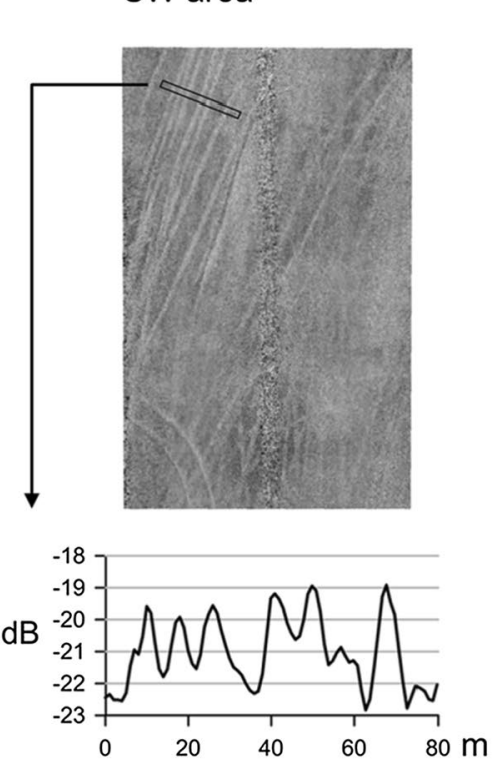

(c)

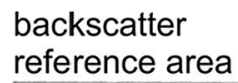

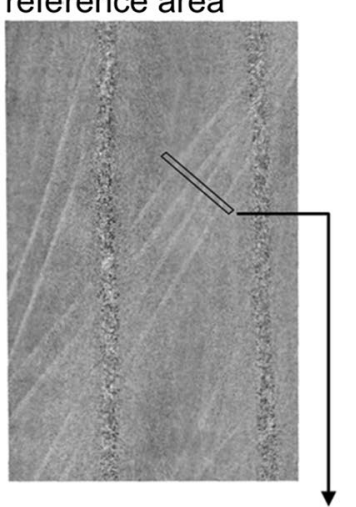

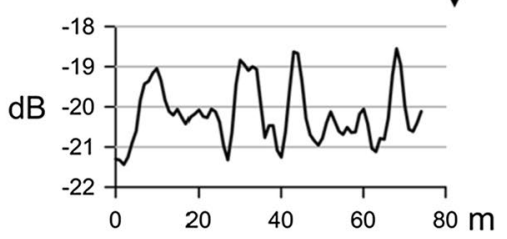

Fig. 11 Trawling marks in the Kwinte reference area revealed by backscatter mosaic. a Overview of the Kwinte area with two zones of interest. b detailed view of the SW area, mean backscatter values along distance of a 5-m corridor cross-section, backscatter maxima coincide with the intersection of the cross-section with the trawl marks, up to $2 \mathrm{~dB}$ separate the maxima from the mean background level. c same as b for the backscatter reference area, the four backscatter maxima observed on the cross-section match the four trawling marks. (Data recorded by the FPS Economy-Continental Shelf service with RV Belgica Kongsberg EM 3002-D, cruise \# C2009/0626/02/2009)

on two surveys (RV Belgica cruises \# 2009/06-26/02/2009 and \# 2015/16-16/12/2015) of the time series but they do not affect the mean backscatter level and standard deviation of the entire area (Fig. 11). In this case, the limitations of the overall statistical approach that considers the mean and the standard deviation, become apparent. In addition to this overall statistical approach, in areas where trawling activities are suspected, images of high-resolution mosaics should 
always be examined to assess the spatial extent of the seabed affected by these activities. On the Kwinte area, the detected trawling marks on one survey are no longer visible on the following survey, suggesting a mechanism of restoration of the seabed within a period of several months. However, taking into account the numerous trawling marks observed in the channels bordering the sandbanks of the Belgian part of the North Sea, it is highly probable that over the long term, the seabed morphology of these gravel areas will be partly shaped by the cumulative impact of trawl fishery.

\section{Western solent reference area}

The Western Solent area is located between the south coast of mainland England and the Isle of Wight, west of Cowes (Fig. 2a, c). The area is orientated SW to NE and covers an area of $1.3 \mathrm{~km}$ by $2.5 \mathrm{~km}$; within this large zone, the
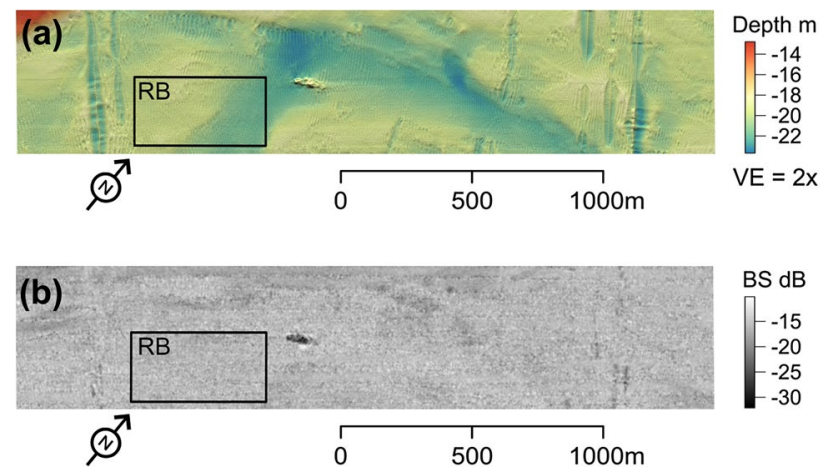

Fig. 12 Bathymetry and backscatter of the Western Solent reference area; RB: reference sub-area for the backscatter. a Bathymetric model (resolution $1 \times 1 \mathrm{~m}$, vertical exaggeration $\mathrm{VE}=2 \mathrm{x}$ ). b Backscatter mosaic (resolution $1 \times 1 \mathrm{~m}$ ). (Data from RV Belgica cruise \# C2015/16 EM 3002-D survey; 12 June 2015) proposed backscatter reference area has a size of $275 \mathrm{~m}$ by $375 \mathrm{~m}$.

The backscatter reference area is characterized by a cobbled pavement which is ridged by long-wavelength $(10 \mathrm{~m})$ medium dunes (sensu Ashley 1990) (Fig. 12a, b). The dune pattern is very stable and in surveys over the previous eight years (approximately one per year) no significant changes have been observed. Figure 13 presents two bathymetric models from 2010 to 2015 with the ridge crests identified. All minor discrepancies of position can be attributed to navigational error or bathymetric and processing uncertainty. The area has a strong tidal current of up to $2 \mathrm{~m} / \mathrm{s}$ which removes any fine-grained accretionary material but does not seem to be erosional. Where the seafloor has been disturbed by trenching for pipelines, significant erosion can be observed, but this is outside the chosen backscatter reference area.

The whole area has depths between 11 and $24 \mathrm{~m}$ but the smaller recommended reference area has only a 4-m depth range (19-23 m). The dunes are approximately $0.5 \mathrm{~m}$ from trough to crest and a wavelength of $10 \mathrm{~m}$ and therefore the average slope is roughly $12^{\circ}$. A survey direction of $53^{\circ}$ or $233^{\circ}$ ensures an insonification parallel to the mean dunes direction. Located close to the National Oceanographic Centre in Southampton (NOC), the Western Solent reference area is regularly surveyed for teaching and research purposes with various MBES. For this area, in the current state, it is not possible to present a time series of average levels of backscatter based on a same MBES with constant acquisition parameters. A complete survey of the area has been done with the RV Belgica EM 3002-D on 13 June 2015. The reference area was crossed along two azimuths (NE-SW and NW-SE).

The Kongsberg EM 3002 can transmit with four different pulse lengths $(50,100,150$ and $200 \mu \mathrm{s})$. Test lines with different pulse lengths have been sailed on the area using the
Fig. 13 Same scale and azimuth for $a, b$ and c. a 2010 MBES survey of part of the Western Solent backscatter reference area. b 2015 higher resolution MBES survey of the same area. c Digitized crests of dunes from both surveys $(2010=$ red, $2015=$ blue). The high spatial correlation of the main crests is noticeable

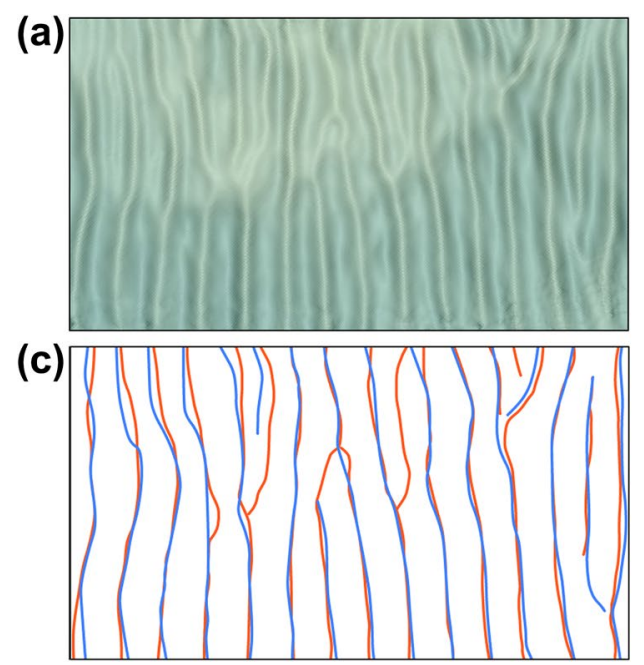

(b)
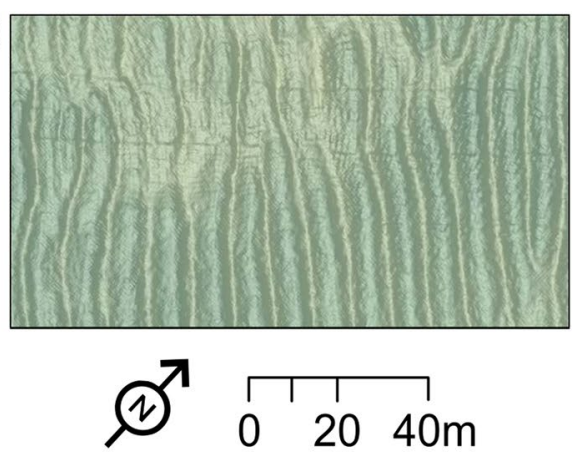

2015

2010 
same NE-SW azimuth of navigation in order to evaluate empirically the effect on the backscatter level (Table 4a). The mean backscatter level changes by $3 \mathrm{~dB}$ between the measurements at $50 \mu$ s and 150 or $200 \mu$ s. Such a change in level, due to changes in the sonar settings, is not acceptable in a monitoring context. Between 150 and $200 \mu$ s the mean backscatter levels differ by only $0.1 \mathrm{~dB}$ and hence both are compatible. Measurements at $100 \mu$ s differ by $1 \mathrm{~dB}$ compared to the other pulse lengths. These results confirm the importance of using a fixed pulse length from one survey to another to ensure the comparability of the mean backscatter level.

Reversing the track azimuth generates significant changes in the standard deviation level (Table $4 \mathrm{~b}$ ), while the average value remains stable.

\section{Discussion: the case for backscatter reference areas}

A summary of the available information on Carré Renard, Kwinte and Western Solent backscatter reference areas is presented in Table 5. The information forms a basis to determine the prevailing criteria for the selection of a natural reference area usable for evaluating the repeatability of backscatter measurements acquired by MBES.

For each area, the averaged backscatter level provides a reference for data from subsequent surveys; in addition, the standard deviation variation gives an estimate of the data dynamics. The carrying vessel, MBES type, pulse length and navigation azimuth used during acquisition as well as the software settings and processing mode are all critical factors that must be specified.

Taking into account all the data available on each area reveals the difficulty for a reference area to meet all the criteria required (Table 1). In particular, on the Carré Renard and Kwinte areas, which have been the subjects of numerous measurements, the bathymetric and backscatter time series combined with in situ observations lead to reconsider certain criteria mentioned in Table 1, which are not strictly respected.

Carré Renard presents all the essential criteria required for a robust reference area; in particular the average backscatter level proves to be remarkably stable. However, the bathymetric time series reveals a slight but significant trend which could be related to siltation of the area as suggested by the significant mud content of the sediment samples (RV Belgica cruise \#16 report 2015). Although not impacting today the backscatter stability, such a trend is not prohibitive as long as a regular monitoring of the area is maintained in order to control the backscatter evolution and thus ensure the predictability of the mean backscatter level.

The Kwinte area presents several physical characteristics similar to Carré Renard. On both areas the seabed is flat, gravelly and acoustically isotropic. The bathymetry and backscatter time series from Kwinte show a remarkable stability, comparable to Carré Renard for average backscatter level and slightly better for bathymetry. So Kwinte is validated as an excellent calibration area. However, the sporadic presence of trawling traces implies a regular mapping of the area in order to monitor the impact of fishery activity.

Presently, the backscatter stability of the Western Solent area cannot be confirmed because no time series acquired with the same echosounder is available. However, the very coarse nature of the seabed, its bathymetric and morphological stability as well as its strong tidal dynamics preventing any accretion of fine sediment together advocate for a satisfactory stability of the backscatter for this area. The backscatter response of this area will have to be monitored in the upcoming years if this area becomes an operational area for calibration.

In Northwestern European coastal areas, the impact of human activities on the seabed cannot be ignored. The potential effect on the stability of the seabed backscatter depends on the substrate and the intensity and type of activity. The introduction, within the framework of a marine spatial plan, of an area set aside for acoustic tests where any other human activity is prohibited, is the ideal solution
Table 4 Comparison of mean level and standard deviation of backscatter data recorded in June 2015 by RV Belgica EM 3002-D on the Western Solent reference area using different settings

\begin{tabular}{|c|c|c|c|c|c|c|c|}
\hline \multicolumn{4}{|l|}{$\mathrm{a}$} & \multicolumn{4}{|l|}{$\mathrm{b}$} \\
\hline Azimuth & $\begin{array}{l}\text { Pulse } \\
\text { length } \\
(\mu \mathrm{s})\end{array}$ & Mean level dB & Std $(\mathrm{dB})$ & Pulse length $\mu$ s & Azimuth & Mean level dB & Std $(\mathrm{dB})$ \\
\hline \multirow[t]{4}{*}{ NE-SW } & 50 & -19.47 & 1.98 & 150 & NE-SW & -16.37 & 1.68 \\
\hline & 100 & -17.24 & 1.72 & & NW-SE & -16.25 & 3.77 \\
\hline & 150 & -16.37 & 1.68 & 200 & NE-SW & -16.27 & 1.99 \\
\hline & 200 & -16.27 & 1.99 & & NW-SE & -16.24 & 3.06 \\
\hline
\end{tabular}

Data processed with QPS Fledermaus FMGT® 7.6.3

a-Same navigation azimuth, different pulse lengths

b-Using 150 and $200 \mu$ s pulse lengths, according to two different navigation azimuths 
Table 5 Synthesis of the main characteristics of the backscatter reference areas Carré Renard, Kwinte and Western Solent

\begin{tabular}{llll}
\hline & Carré Renard & Kwinte & Western Solent \\
\hline Backscatter mean level & $-16.0 \mathrm{~dB}$ & $-17.4 \mathrm{~dB}$ & $-16.3 \mathrm{~dB}$ \\
Backscatter mean standard deviation & $1.5 \mathrm{~dB}$ & $2.5 \mathrm{~dB}$ & $1.8 \mathrm{~dB}$ \\
Based on & & & \\
Vessel & RV Thalia & RV Belgica & RV Belgica \\
MBES & EM2040 & EM3002-D & EM3002-D \\
Frequency & $300 \mathrm{kHz}$ & $300 \mathrm{kHz}$ & $300 \mathrm{kHz}$ \\
Pulse length & $100 \mu \mathrm{s}$ & 150 and $200 \mu \mathrm{s}$ & $150 \mathrm{and} 200 \mu \mathrm{s}$ \\
Survey line azimuth & Isotropic & Isotropic & $53^{\circ}$ or $233^{\circ}$ \\
Processing Software & SonarScope® & SonarScope® & QPS FMGT® \\
Processing method & See Table 2 & See Table 2 & Default settings \\
In angular sector & {$\left[30^{\circ} 50^{\circ}\right]$} & {$\left[30^{\circ} 50^{\circ}\right]$} & Full \\
Bathymetric stability inside IHO SO & No & Yes & Not confirmed \\
Morphologic stability & Yes & Yes & Yes \\
Time series & Yes & Yes & Yes \\
Bathymetric trend & Yes-slight & No & Unknown \\
Directional pattern & No & No & Yes \\
Backscatter spatial isotropy & Yes & Yes & No \\
Sediment cover & Muddy sandy Gravel & Sandy Gravel & Cobble \\
Biological component & Important & Moderate & Unknown \\
Seabed anthropic alteration & No & yes-sporadic & No \\
Backscatter stability inside $\pm 1 \mathrm{~dB}$ & Yes & Yes & Unknown \\
Time series available & Yes & Yes & No \\
Backscatter-Trend & No & No & Unknown \\
\hline
\end{tabular}

since it avoids direct impacts (plowing by e.g., trawling or trailing suction hopper dredger, ship anchoring). The impact of human activity in the proximity of the area, generating indirect impacts on the survey conditions and data quality (bubbles, sediment plumes, noise, moorings, or boat traffic on the area) needs careful consideration. The protection of the Kwinte reference area from all human activities and its integration as a scientific reference area in the Marine Spatial Plan for the Belgian part of the North Sea (Federal Public Service Health, Food Chain Safety and Environment 2014) has been introduced in the new Marine Spatial Plan release which will apply in 2020.

Practically, a reference area needs to be easily accessible for survey vessels and should ideally coincide with areas already used in hydrography for bathymetric calibration and quality control tests. Accessibility does not only refer to sailing distance from neighbouring harbors. In an "openscience perspective", a well-documented reference area for which a robust time series of bathymetric and backscatter data is available will attract international interest. Research and survey vessels from neighboring countries should be able, using simple procedures, to calibrate their systems on a common area. The creation of a network of reference areas should be envisaged in the framework of transnational collaborative projects.

The possibility of using a stable reference area which can be rapidly surveyed to control the stability of the measurement systems without affecting too much the overall survey planning, will depend on the regional context (closeness to the home port) and on the logistic constraints. Another pragmatic and straightforward approach is to use a reference line surveyed systematically when the vessels leave or enter the harbor (Weber et al. 2017).

Upstream in the acquisition and processing process, the control of the backscatter stability over a reference area requires defining MBES acquisition parameters adapted to the operational objectives and preserving these acquisition parameters from one survey to another. This is a critical point, a condition that must be the subject of sustained attention throughout the monitoring program by those in charge of MBES data acquisition aboard research vessels. The comparative measurements carried out on the Western Solent area with the RV Belgica EM3002-D illustrate the fact that, without such precaution, data may be impossible to compare if their pulse lengths differ too much: for the EM3002 only the emission lengths of 150 and $200 \mu$ s are compatible. Building a roadmap describing and comparing backscatter levels from the various available settings is necessary to ensure unequivocal inter-comparability of final values.

Downstream, in the absence of absolute calibration usable as a single reference to correct each of the surveys, the average backscatter level in the most discriminating angular range $\left( \pm\left[30^{\circ}, 50^{\circ}\right]\right)$ can be estimated from the raw signal corrected only for the attenuation and the insonified surface but free of any adaptive corrections, of beam-pattern corrections and angular compensations. 
Finally, deciding whether the backscatter measurements by a given system pass the repeatability test obviously depends on the choice of a reference value and an allowed tolerance. In a long-time series, the average of the mean backscatter levels of all accepted measurements is a natural and robust reference. The calculation of an average backscatter model, based on all the angular sector values of the surveys included in the analysis, provides a reference surface for the reference area. The use of this reference model enhances the repeatability test with a spatial component, which enables the detection of spatial variations. A large deviation on a limited part of the reference area, possibly caused by natural phenomena or human intervention, can have a large impact on the mean and standard deviation, but remains unnoticed without the use of a reference model. The discussed and proposed threshold of $\pm 1 \mathrm{~dB}$ around the reference value or model is a justifiable choice, based on the technical and sedimentological significance and the independence of the number of measurements. The observed trends exceeding the $\pm 1 \mathrm{~dB}$ interval around the overall mean on some backscatter time series acquired on sand extraction monitoring areas of the Belgian part of the North Sea (Roche et al. 2017) validate this approach.

If a trend of the mean backscatter level is observed on a proposed reference area with a single system, a control with another MBES is necessary to discriminate if the trend is due to variation in the seabed or a drift of the sensitivity of one MBES. The likelihood that two independent acoustic systems measuring backscatter echoes from the same area of seabed present a same drift due to a simultaneous loss of sensitivity is very low.

\section{Conclusion}

The benefits of using backscatter natural reference areas are plenty. They provide a simple and pragmatic solution to ensure the repeatability of the MBES measurements. They can be used to perform either repeatability control or absolute calibration. The MBES is operated under operational conditions over a real natural target. It is an inexpensive and fast operation, easy to integrate at the start of a survey in order to ensure the correct status of the MBES; it can be coupled with the bathymetry calibration routine procedure, and conducted on the same area.

Not all requirements for a backscatter reference area, listed at the start of this paper (Table 1), are necessary to conclude if an area is suitable for this use. The Kwinte and Carré Renard areas demonstrate that the predominant criterion is the acoustic stability, characterized by a stable mean and standard deviation of the backscatter values, and demonstrated in a long and continuous time-series. The other requirements contribute to the suitability of the area, but can be worked around if certain environmental conditions impose a less than ideal area.

However, the establishment of a reference area implies a significant investment by the parties involved in the field of data exchange and management. Practically, the definition, initial characterization, monitoring and management of each reference area are the responsibility of a specific organization or group of interested parties. Establishing a network of calibration zones could facilitate the use of these areas by all involved actors of the domain, allowing calibration and repeatability checks of any MBES used in international campaigns and research programs. Making it mandatory for monitoring or mapping programs contractors to regularly survey reference areas to calibrate their sonar systems would send a strong and positive message to the marine surveying and science communities about the importance of quantitative backscatter signal acquisition and processing and represent a big step forward in the area of research.

Acknowledgements The crew of the RV Belgica is thanked for the numerous campaigns dedicated to MBES data acquisition. The Operational Directorate Natural Environment (former Management Unit of the Mathematical Model of the North Sea and the Scheldt Estuary$\mathrm{BMM}$ ) provided the necessary logistic and ship time on board the RV Belgica. Dimitrios Eleftherakis (Ifremer) is thanked for his constructive support and numerous exchanges on the subject. The authors thank the reviewers for having carefully reviewed the manuscript and for their constructive suggestions.

Open Access This article is distributed under the terms of the Creative Commons Attribution 4.0 International License (http://creativecommons.org/licenses/by/4.0/), which permits unrestricted use, distribution, and reproduction in any medium, provided you give appropriate credit to the original author(s) and the source, provide a link to the Creative Commons license, and indicate if changes were made.

\section{References}

APL (1994) Applied Physics Laboratory; High-frequency ocean environmental acoustic models. APL-UW TR 9407-AEAS 9501. University of Washington

Ashley GM (1990) Classification of large-scale subaqueous bedforms: a new look at an old problem-SEPM bedforms and bedding structures. J Sediment Res 60:160-172

Augustin JM (2016) SonarScope ${ }^{\circledR}$ software on-line presentation. http://flotte.ifremer.fr/fleet/Presentation-of-the-fleet/Logicielsembarques/SonarScope. Last accessed 10/01/2017

Blanchet-Aurigny A, Dubois SF, Hily C, Rochette S, Le Goaster E, Guillou M (2012) Multi-decadal changes in two co-occurring ophiuroid populations. Mar Ecol Prog Ser 460:79-90

Dronkers JJ (2016) Dynamics of coastal systems. Netherlands Centre of Coastal Research, Advanced series on ocean engineering. World Scientific, New Jersey

Eleftherakis D, Berger L, Le Bouffant N, Pacault A, Augustin J-M, Lurton X (2018) Backscatter calibration of high-frequency multibeam echosounder using a reference single-beam system, on natural seafloor. In: Lamarche G, Lurton X (eds) Seafloor backscatter 
data from swath mapping echosounders: from technological development to novel applications. Springer, New York

Federal Public Service Health, Food Chain Safety and Environment (2014) Marine Spatial Plan for the Belgian part of the North Sea. https://www.health.belgium.be/sites/default/files/uploads/fields/ fpshealth_theme_file/19094275/Summary\%20Marine\%20Spatial\%20Plan.pdf. Last accessed 10/01/2018

Folk RL (1954) The distinction between grain size and mineral composition in sedimentary rock nomenclature. J Geol 62(4):344-359

GEBCO (2014) General Bathymetric Chart of the Oceans-GEBCO 30 arc-second grid. https://www.gebco.net/data_and_products/ gridded_bathymetry_data/gebco_30_second_grid/. Last accessed $10 / 01 / 2018$

Hammerstad E (2000) EM technical note: backscattering and seabed image reflectivity. Kongsberg Maritime AS, Horten, Norway

Hughes Clarke JE (2012) Optimal use of multibeam technology in the study of shelf morphodynamics. Int Assoc Sedimentol Spec Publ 44:1-28

IHO (2008), "IHO Standards for Hydrographic Surveys", 5th edn, February 2008, https://www.iho.int/iho_pubs/standard/S-44_5E.pdf. Last accessed 10/01/2018

Kongsberg (2017a) Kongsberg Maritime Backscatter Calibration Service. https://www.km.kongsberg.com/ks/web/nokbg0238.nsf/All Web/02C2543B366AA18DC12580A4003E288B?Open. Last accessed 10/01/2018

Kongsberg (2017b) Kongsberg Multibeam Echosounders. https://www. km.kongsberg.com/ks/web/nokbg0240.nsf/AllWeb/620F423FA 7B503A7C1256BCD0023C0E5?OpenDocument. Last accessed $10 / 01 / 2017$

Lamarche G, Lurton X (2017) Recommendations for improved and coherent acquisition and processing of backscatter data from seafloor-mapping sonars. In: Lamarche G, Lurton X (eds) Mar Geophys Res Seafloor backscatter data from swath mapping echosounders: from technological development to novel applications. Springer, New York, pp 1-18, https://doi.org/10.1007/ s11001-017-9315-6

Lamarche G, Lurton X, Verdier A-L, Augustin J-M (2011) Quantitative characterization of seafloor substrate and bedforms using advanced processing of multibeam backscatter. Application to the Cook Strait, New Zealand. Cont Shelf Res 31:S93-S109

Land Information New Zealand (2016). Contract Specifications for Hydrographic Surveys, Version 1.3 New Zealand Hydrographic Authority, 7 June 2016, pp 41-95

Liu AC, Missiaen T, Henriet JP (1992) The morphology of the TopTertiary erosion surface in the Belgian Sector of the North Sea. Mar Geol 105:275-284

Long D (2006) BGS detailed explanation of seabed sediment modified folk classification. http://www.emodnet-seabedhabitats.eu/. Last accessed 10/01/2018

Lucieer V, Roche M, Degrendele K, Malik M, Dolan M, Lamarche G (2017) User expectations for multibeam backscatter data-looking back into the future. In: Lamarche G, Lurton X (eds) Mar Geophys Res Seafloor backscatter data from swath mapping echosounders: from technological development to novel applications. Springer, New York. https://doi.org/10.1007/s11001-017-9316-5

Lurton X, Lamarche G (eds) (2015) Backscatter measurements by seafloor mapping sonars: guidelines and recommendations. http:// geohab.org/wp-content/uploads/2013/02/BWSG-REPORTMAY2015.pdf. Last accessed 10/01/2018

Lurton X, Roche M, Le Bas T, Vrignaud C, Degrendele K, Eleftherakis D, Loyer S (2015) Multibeam echosounder calibration for backscatter measurements on seafloor surveys: definition of natural references areas. Proc Inst Acoust 37:311-318
Lurton X, Eleftherakis D, Augustin J-M (2017) Analysis of seafloor backscatter strength dependence on the survey azimuth using multibeam echosounder data. In: Lamarche G, Lurton X (eds) Mar Geophys Res Seafloor backscatter data from swath mapping echosounders: from technological development to novel applications. Springer, New York, pp 1-21. https://doi.org/10.1007/ s11001-017-9318-3

MSFD (2008) Marine Strategy Framework Directive 2008/56/EC of the European Parliament and of the Council. http://eur-lex.europa. eu/legal-content/EN/TXT/PDF/?uri=CELEX:32008L0056\&from $=$ EN. Last accessed 10/01/2017

Palanques A, Puig P, Guillén J, Demestre M, Martín J (2014) Effects of bottom trawling on the Ebro continental shelf sedimentary system (NW Mediterranean). Cont Shelf Res 72:83-98

Rice G, Cooper R, Degrendele K, Gutierrez F, Le Bouffant N, Roche M (2015) Chapter 5-Acquisition: best practice guide. In: Lurton X, Lamarche $\mathrm{G}$ (eds) Backscatter measurements by seafloor mapping sonars. Guidelines Recommendations, pp 106-132. http://geohab. org/wp-content/uploads/2014/05/BSWGREPORT/MAY2015.pdf. Last accessed 10/01/2017

Rivera J, Mateu G, Hermida N, Pomar L, Acosta J (2017) Trawl Marks and Dredge Spoils as of Seabed Anthropic Alteration on Sediments (Menorca Shelf). In: Guillén J et al (eds) Atlas of Bedforms in the Western Mediterranean. Springer, New York, pp 167-172

Roche M (2002) Utilisation du sonar multifaisceaux pour la classification acoustique des sédiments et son application à la cartographie de la zone de concession 2 de la mer territoriale et du plateau continental belge, Etude de Faisabilité. Rapport de stage interne, Ministère des Affaires économiques, Belgique

Roche M, Degrendele K, Vandenreyken H, Schotte P (2017) Multi time and space scale monitoring of the sand extraction and its impact on the seabed by coupling EMS data and MBES measurements. Belgian marine sand: a scarce resource? Belgian FPS Economy-Study day 9. June 2017, pp 5-37. http://economie. fgov.be/fr/binaries/Articles-study-day-2017_tcm326-283850.pdf

RV Belgica Cruise \#16 Report (2015). https://odnature.naturalsciences. be/downloads/belgica/campaigns/reports/re2015_16.pdf. Last accessed 10/01/2018

Stanic S, Briggs KB, Fleischer P, Ray RI, Sawyer WB (1988) Highfrequency acoustic backscattering from a coarse shell ocean bottom. J Acoust Soc Am 85(1):125-136

Tytgat J (1989) Dynamics of gravel in the superficial sediments of the Flemish Banks, Southern North Sea. In: Henriet JP, De Moor G (eds) The quaternary and tertiary geology of the Southern Bight, North Sea, Ministry of Economic Affairs Belgian Geological Survey, pp 217-228

Van den Eynde D, Giardino A, Portilla J, Fettweis M, Francken F, Monbaliu J (2010) Modelling the effects of sand extraction, on sediment transport due to tides on the Kwinte Bank. J Coast Res $51: 101-116$

Vlaamse Hydrografie (2014) Belgische Noordzee van De panne tot Knokke-Heist BNZ 1:100 000 scale

Weber TC, Rice G, Smith M (2017) Toward a standard line for use in multibeam echo sounder calibration. In: Lamarche G, Lurton X (eds) Mar Geophys Res Seafloor backscatter data from swath mapping echosounders: from technological development to novel applications. Springer, New York. https://doi.org/10.1007/ s11001-017-9334-3

World Imagery (2017) http://www.arcgis.com/home/item.html?id=1 0df2279f9684e4a9f6a7f08febac2a9. Last accessed 10/01/2018 